\title{
Absorption and rheological phenomena during foam application on textiles.
}

\author{
J T E Lemmen and J Groot Wassink
}

\author{
University of Twente, Enschede, The Netherlands
}

A simple rheological model has been used to describe foam flow through moving textile assemblies. The validity of this model was tested, and the nature and the relative magnitude of deviations from the model evaluated for several different substrates. Neglecting foam degeneration during transport, the model was found to represent a valuable means of evaluating some rheological and geometrical deviations. The model can be used in a semi-quantitative way to describe absorbency during foam application. Liquid absorption experiments done off-line, absorption during foam application and some earlier results could be described using different theoretical approaches. Some rheological anomalies have been discussed.

\section{INTRODUCTION}

The application of semi-stable foams to textiles and similar substrates has been studied since the revival of foam finishing at the beginning of the 1980s. Many of the typical parameters important in the interaction of foam with a substrate can best be studied in application from a closed system [1]. In this paper we continue this study in a more quantitative way using a simple model in an attempt to understand and describe the deviations from this model. As the model only describes the flow of a $100 \%$ stable foam through a non-absorbent substrate we have found a number of deviations from this ideal situation. These include foam degradation, causing viscosity decrease and possibly the formation of liquid boundary layers resulting in slip flow. On the substrate there are effects from absorption, wetting, swelling and liquid retention. This investigation deals with the dynamic application of foam to different substrates, making it possible to differentiate between these effects.

\section{MODEL}

The model is based on the assumption that foam rheology can be adequately described by the power law (Eqn 1):

$$
\tau=k \dot{\gamma}^{n}
$$

revealing the shear thinning character of foam and neglecting the contribution of yield stress and elastic behaviour, as was accounted for in earlier research [2]. This rheological relationship was coupled with factors relating to the capillary flow of foam into a moving substrate consisting of parallel capillaries [3], leading to the Eqn 2 to describe pressure drop across the substrate:

$$
\begin{gathered}
P=\frac{C}{K}\left(\frac{n}{n+1}\right)^{n} \frac{\phi_{\mathrm{v}}{ }^{n+1}}{v} \quad \text { for } \phi_{\mathrm{v}} \leq K v \text { and } \\
P=C\left(\phi_{\mathrm{v}}-\frac{K v}{n+1}\right)^{n} \quad \text { for } \phi_{\mathrm{v}} \geq K v
\end{gathered}
$$

The model can be seen to consist of two parts separated by a geometric boundary condition. The first part describes the penetration of foam into the capillaries of the substrate without reaching its back. The second part accounts for the situation where foam lays on the back of the fabric without contributing to pressure build-up.

\section{EXPERIMENTAL}

\section{Mode of application}

Foam generated in a rotor-stator mixer was applied to the substrate from a rectangular slit of width $\lambda$ and length $b$ over which the fabric was transported with velocity $v$ in such a way that the slit was completely sealed by the fabric, thus preventing foam flow anywhere but through the fabric [1]. Most applications were done on a freerunning fabric, not supported by a rubber belt.

\section{Chemicals}

Three surfactant formulations where used:

1. A mixture of $16 \mathrm{~g} /$ Sandopan $\mathrm{KD}$ (an anionic modified alkylpolyglycolether) with $16 \mathrm{~g} / \mathrm{l}$ Sandopan LFW (a non-ionic alkylpolyglycolether)

2. $10 \mathrm{~g} / \mathrm{l}$ sodium dodecyl sulphate

3. A mixture of $10 \mathrm{~g} / \mathrm{l}$ sodium dodecyl sulphate with $2.5-$ $3 \mathrm{~g} / \mathrm{l}$ dodecanol (lauryl alcohol), only effectively stabilised at a temperature above $26^{\circ} \mathrm{C}$.

To obtain a visual judgment of the finished fabric $4 \mathrm{~g} /$ Erio Green (CGY, CI Acid Green 16) was added, which was assumed to have no effect on foam rheology or interaction with the textile. Unless stated otherwise, formulation 1 was used.
Substrates
A Polyester/nylon non-woven made up of polyester fi-
bres with a $30 \%$ nylon coating of $40 \mu \mathrm{m}$ mean diameter
B Polyester monofilament woven fabric
C Polyester multifilament woven fabric 
D Polyester/cotton (65:35) woven staple fabric

E Cotton woven fabric.

The properties of the substrates used are given in Table 1.

Table 1 Estimated and approximate value of several parameters of the fabrics used

\begin{tabular}{|c|c|c|c|c|c|}
\hline Sample & $\begin{array}{l}\text { Fabric } \\
\text { weight } \\
\left(\mathrm{g} / \mathrm{m}^{2}\right)\end{array}$ & Porosity & $\begin{array}{l}\text { Fabric } \\
\text { thickness } \\
(\mathrm{mm})\end{array}$ & $\begin{array}{l}\text { Warp } \\
\left(\mathrm{cm}^{-1}\right)\end{array}$ & $\begin{array}{l}\text { Weft } \\
\left(\mathrm{cm}^{-1}\right)\end{array}$ \\
\hline A & 220 & 0.80 & 0.8 & & \\
\hline B & 140 & 0.56 & 0.23 & 39.4 & 39.4 \\
\hline C & 80 & 0.58 & 0.1 & 18.5 & 16.0 \\
\hline D & 260 & 0.30 & 0.45 & 27.4 & 15.5 \\
\hline E1 & 130 & 0.40 & 0.20 & 54.1 & 24.8 \\
\hline E2 & 130 & 0.40 & 0.20 & 45.0 & 40.0 \\
\hline
\end{tabular}

\section{RESULTS AND DISCUSSION}

\section{Non-absorbent; non-woven (A)}

From the chemical nature of the fibres we expected no significant absorbency into the fibre to occur. From the geometrical construction, i.e. a mass of arbitrarily distributed fibres with small islands of higher concentration, some preferential retention of liquid was expected to occur in the fibre mass.

Pressure measurements on running fabric satisfied the model and the appearance of foam on the back of the fabric occurred very near to the boundary condition (Figure 1). At low speed (high wet pick-up) a relatively greater pressure drop was observed, probably due to foam flow resistance from the larger water retention of the fabric. At this point the pressure drop on the moving substrate approached the pressure drop on the stationary substrate. Using $n$ values from independent rheological measurements we calculated a coefficient of resistance $C$ for different foam densities [4]. This was proportional to foam consistency $k$ [3]. We found that $C\left(\rho_{\mathrm{f}}=25 \mathrm{~g} / \mathrm{l}\right)<\mathrm{C}\left(\rho_{\mathrm{f}}=50 \mathrm{~g} / \mathrm{l}\right)<\mathrm{C}\left(\rho_{\mathrm{f}}=100 \mathrm{~g} / \mathrm{l}\right)$, in spite of the fact that from independent measurement it would follow that $k\left(\rho_{\mathrm{f}}=25 \mathrm{~g} / \mathrm{l}\right)>k\left(\rho_{\mathrm{f}}=50 \mathrm{~g} /\right)>k\left(\rho_{\mathrm{f}}=100 \mathrm{~g} /\right)$. Part of this anomaly could be ascribed to the influence of $n$ itself on $C$ but still a large difference remained to be explained. A similar result also has been found for the flow of foam through stationary substrates [3]. The solution to this problem is probably to be found in a combination of foam viscosity decrease during application and the influence of bubble size distribution. Foam viscosity decrease over time (residence time from mixer to application point) depends on the shear rate applied. Assuming turbulent mixing conditions during foam generation, the mean bubble diameter increases with decreasing density [5] which in conjunction with a specific substrate may lead to substantial loss of pressure [4]. The phenomenon occurred with stationary substrates where the $C$ value for all three densities were almost the same.
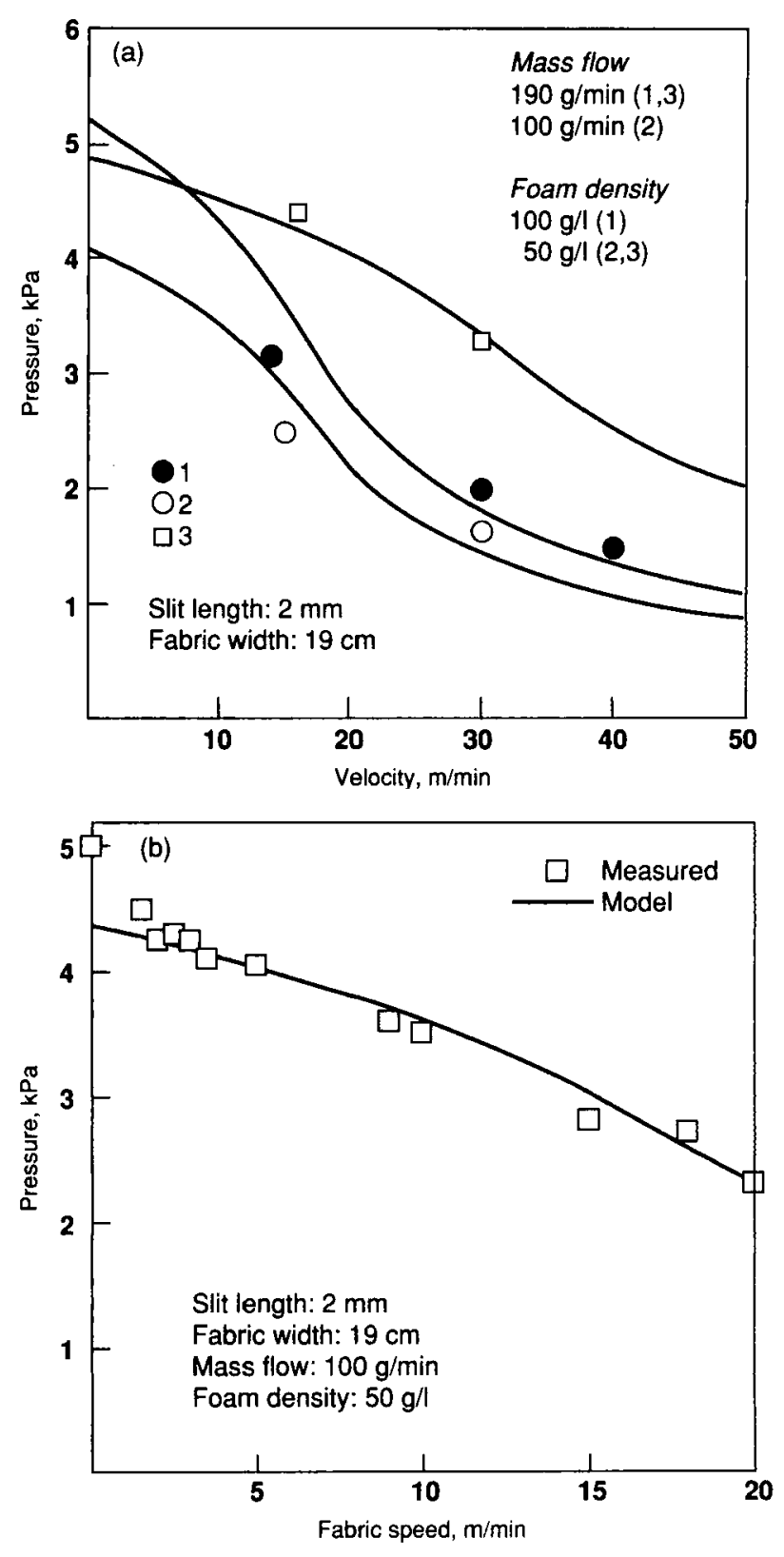

Figure 1 Non-woven: (a) model without absorption, (b) foam application at low speed

\section{Non-absorbent; monofilament woven fabric (B)}

This type of substrate is geometrically more similar to an ordinary cotton fabric and, unlike a non-woven, is made up of a discrete number of holes or capillaries through which laminar flow can be assumed. Having no or little absorptive capacity (regain $\approx 0.4 \%[6,7]$ ), the boundary condition is exactly satisfied. Taking this boundary situation as an internal standard for a certain foam quality, we found that at all rates of foam flow the pressure drops over the fabric were lower (Figure 2). For foam flow below the boundary value, we propose that the main reason for this is the geometric deviation from the model. It was assumed that all channels in the substrate were of uniform cross-section, thus contributing to the pressure build-up equivalent to their degree of filling [3]. While the holes between fibres in a woven structure become wider near the substrate surface, a relatively lower pressure drop is likely to occur when they are only partly 


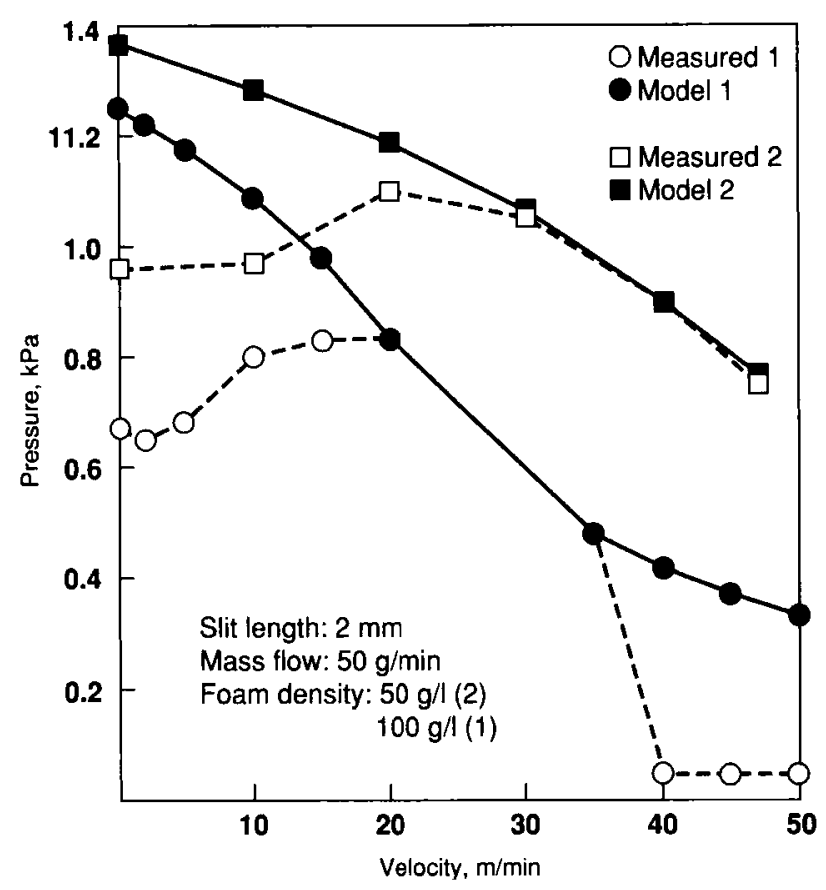

Figure 2 Non-absorbing fabric: model and measurements

filled, as is the case for flow below the boundary value.

Above the boundary value this geometrical deviation becomes less important. Because the experimental set-up was one of variable fabric speed at constant foam flow, the foam flow conditions in the substrate did not change significantly. Therefore the pressure decrease in this situation must have a rheological cause. Having little absorption capacity and a relatively small surface area (no crevices/smooth surface), it is possible to imagine the development of a liquid boundary layer at this surface, leading to slip flow. A layer of a few microns would be enough to give a substantial decrease in of pressure drop. Using the Reynolds number for boundary layer behaviour $[8,9]$, we have found that pure water can readily form a thick layer, but in this case it would be limited and governed by the amount of water available in the foam and the readiness of the foam to release it [10]. Thus the conditions for development of a relevant liquid layer are as follows:

- relatively small surface area (woven cf. non-woven)

- relatively unstable foam (fast breaking cf. stabilised)

- relatively high water add-on (high wet pick-up).

While foam formulation 1 led to the most unstable foams of the three formulations used, application to substrate $B$ was the most favourable for the development of liquid slip flow layers resulting in appreciable loss of pressure. Instead of a liquid layer, a large increase in foam density would have almost the same effect, but would be more gradually in nature. The same effect of foam density was found as with application on the non-woven.

\section{Absorbing fabrics (C, D, E)}

After determining the effects of water retention, slip flow and foam density, we concentrated on the effect of absorbency. All other effects would still be important for some specific applications. The lightweight polyester multifilament woven fabric $(C)$, geometrically somewhere between a non-woven and a woven structure, exhibited some absorptive capacity between the filaments. Because these filaments were still quite smooth, it offered a possibility for liquid boundary flow. Both effects seem to have been present (Figure 3).

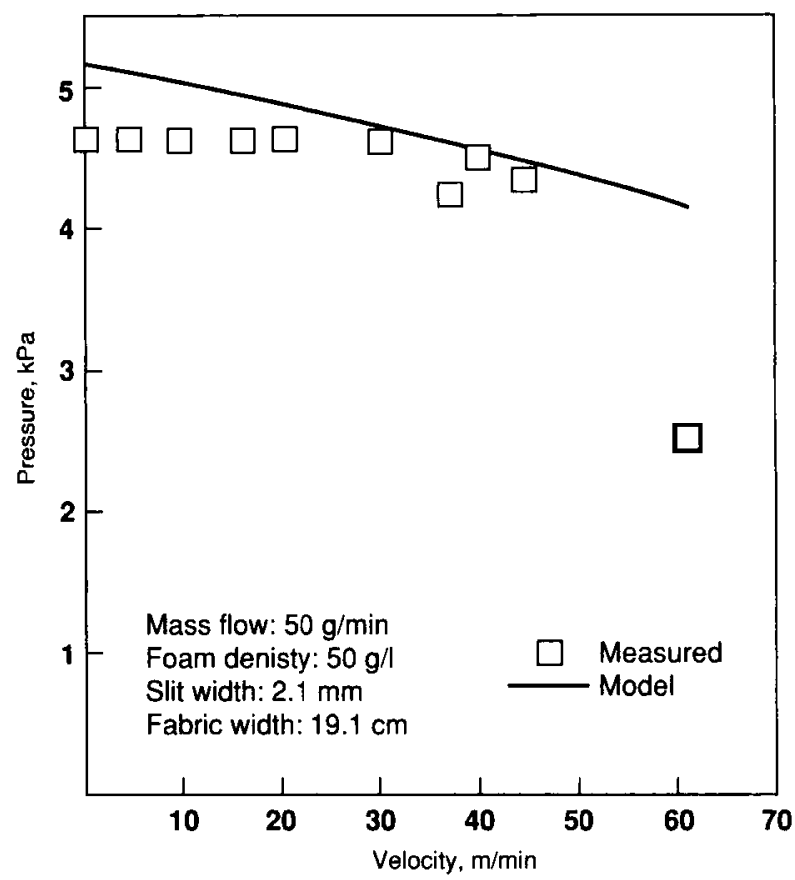

Figure 3 Polyester, multifilament woven fabric

The absorbency of a polyester/cotton mixture (D) did not arise only from the capillaries between the fibres but also from the absorptive nature of the cotton fibres themselves. Here also all effects are observed (Figure 4).

The application of foam to $100 \%$ cotton fabrics (two types, E1 and E2, both desized and bleached) led to a substantial decrease in pressure drop in all cases but the highest wet pick-up (Figure 5).

\section{Absorbency}

The absorbency of water into textile (cotton) assemblies is not yet fully understood but the following sequence of events is likely to be of importance. First the liquid must be forced to penetrate the gauze porosity of the assembly. Next several effects may occur simultaneously: penetration into the capillary system of fibres which make up the yarns, wetting of the yarns (outside) and the capillary system inside of them, and absorption of liquid into the fibres (regain, swelling). In textile finishing it is normal to add surface-active chemicals to promote wetting and capillary action. The contact angle between solid (the fabric) and liquid should be small or zero to enable liquid spreading; at the same time the surface tension in the capillaries should be sufficiently high to maintain capillary pressure. Whilst these are opposing conditions, it is generally accepted that it is necessary to strive for the optimum balance.

In our foam penetration model the first step is already 


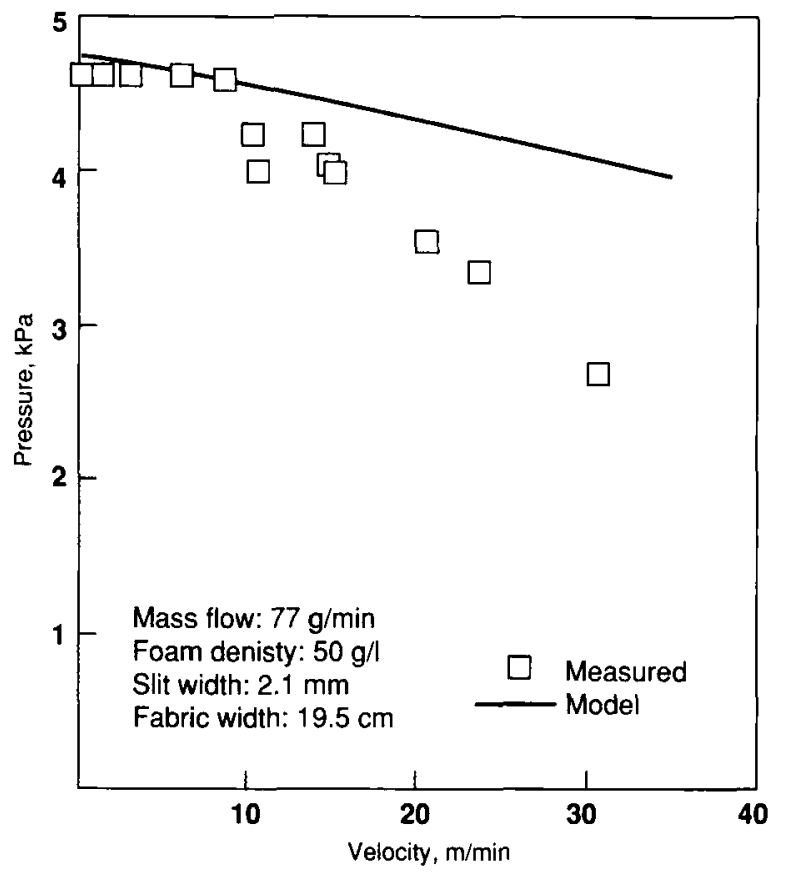

Figure 4 Polyester/cotton fabric: effect of absorption

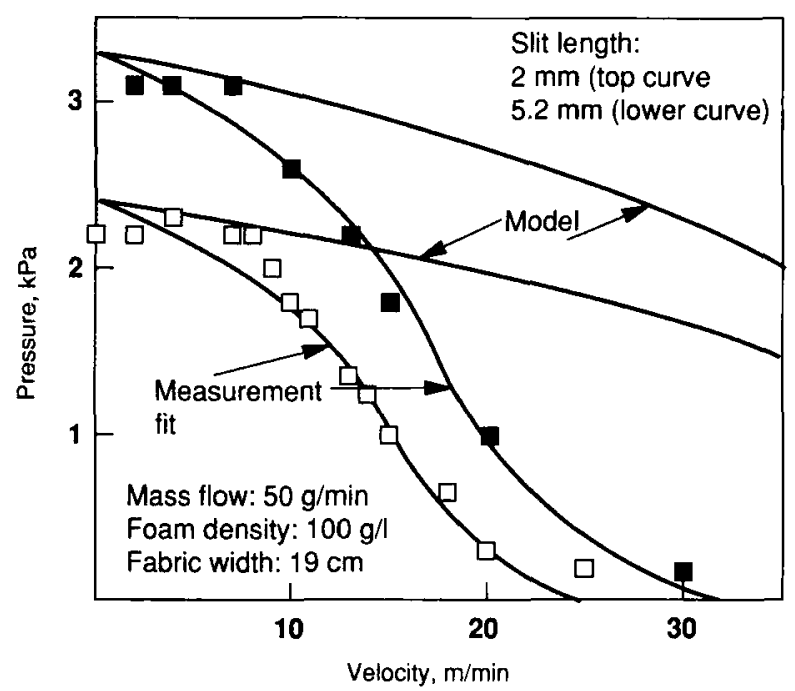

Figure 5 Cotton: absorption versus velocity at constant foam flow

accounted for, i.e. the penetration of the fluid into the substrate. The overall effect of all other types of absorbency lead to deviation from the model pressure drop.

While wetting is governed by interfacial tension instead of surface tension of the liquid alone, it is chemically specific and thus hard to predict beforehand. To obtain an idea of the overall effect of absorbency in foam textile interaction we used a modification of the method of Miller $e t$ al. to measure unforced uptake of water by fabrics [11]. Miller's method to determine 'spontaneous transplanar uptake' or 'demand wettability' consists of a horizontal porous plate (filter) on which the substrate is laid and from which liquid is offered under a negative pressure head. We were more interested in the unforced uptake of liquid so we tried to maintain a zero static pressure head. Before discussing the possible ways of evaluating these measurements we first need to state some experimental problems.
We are chiefly interested in the absorbency in the first $0.1 \mathrm{~s}$. Because the absorption process is measured as a gravimetrical change, we could not measure more frequently than once every 0.1 to $0.4 \mathrm{~s}$ (depending on the measuring device used). There was similar problem with inertial forces inside the capillaries. This problem has been adequately discussed by both Szekely and Chwastiak and must lead to the conclusion that for absorption times less than 10-100 ms no reliable equation can be derived without accounting for the effect of inertial forces $[12,13]$.

Another experimental difficulty is the capillary action originating from sources other than the yarns, e.g. between the yarns themselves and between the substrate and the plates on which it was positioned. This capillarity is probably responsible for the high wet pick-up of over $200 \%$ for cotton. Furthermore the resistance to flow of the porous plate played an important role at higher liquid flows. This can be quantified by a filter conductance coefficient $C_{\mathrm{f}}$ defined by Eqn 3:

$$
C_{\mathrm{f}}=\frac{\phi_{\mathrm{m}}}{S \Delta P}
$$

From this definition it can be seen that, although the liquid may be offered with zero static pressure at higher flow rates, a significant dynamic pressure may develop, as was indeed found. In his original paper Miller used static pressure gradients of $1 \mathrm{~cm} \mathrm{H}_{2} \mathrm{O}(\approx 98 \mathrm{~Pa})$ and more, and used a perforated plate with filter coefficients of the same order of magnitude $\left(0.75-7.8 \mathrm{mg} / \mathrm{s}, \mathrm{cm}^{2}, \mathrm{cmH}_{2} \mathrm{O}\right)$ as we $\operatorname{did}\left(C_{f}=2\right.$ and 16). He somewhat obscured the effect of $C_{\mathrm{f}}$ because no measurement results were reported at zero static pressure.

There are several possible ways to evaluate absorption in textile assemblies. One is to describe this type of mass transfer as a diffusion process following Fickian kinetics, as has been suggested by Chatterjee [14]. The basic equation becomes Eqn 4:

$$
\frac{\partial s}{\partial t}=\frac{\partial}{\partial x}\left[F(s) \frac{\partial s}{\partial x}\right]
$$

Solutions to this differential equation have been summarised for several cases by Crank [15]. Besides graphical solutions Crank gives short-term (Eqn 5) and a long-term (Eqn 6) analytical solutions for a constant diffusion coefficient into a plane sheet with a uniform initial distribution (zero in our case) and equal surface concentrations. This solution also applies to our case since absorption was exactly half of the symmetrical situation described by Crank (Eqns 5 and 6 ).

$$
\begin{aligned}
\frac{M_{t}}{M_{\infty}} & =2\left(\frac{D t}{l^{2}}\right)^{1 / 2}\left[\frac{1}{n^{1 / 2}}+2 \sum_{n+1}^{\infty}(-1)^{n} \text { ierfe } \frac{n l}{(D t)^{1 / 2}}\right] \\
& \approx \frac{2}{l}\left(\frac{D t}{\pi^{2}}\right)^{1 / 2}
\end{aligned}
$$

Eqns 5 and 6 and the well known Washburn equation, often used in the simplified form shown in Eqn $7[13,16]$, 


$$
\begin{gathered}
\frac{M_{t}}{M_{\infty}}= \\
1-\frac{8}{\pi^{2}} \sum_{n=0}^{\infty} \frac{1}{(2 n+1)^{2}} \exp \left(-D(2 n+1)^{2} \pi^{2} t / 41^{2}\right) \\
M_{t} \approx L=\left(\frac{R \sigma \cos \phi}{2 \eta}\right)^{1 / 2} t^{1 / 2}
\end{gathered}
$$

have the principal objection that they do not account for the inertial forces at the start of the process. Although they agree qualitatively in their description of absorption being proportional to $t^{1 / 2}$, they have a fundamental imperfection since they predict a flow rate of infinity at $t=$ 0 , which is clearly impossible. Szekely [12] accounted for this effect by stating a boundary condition in his secondorder differential equation: $\mathrm{d} L / \mathrm{d} t=0$ at $t=0$, being equivalent to a zero flow rate.

We used a simpler method to describe the process in the time interval between 0 and $100 \mathrm{~ms}$. Following the suggestion of Morton and Hearle [8], we assumed mass transfer to occur under its own gradient (Eqn 8):

$$
\frac{\mathrm{d} M_{t}}{\mathrm{~d} t} \approx M_{t}-M_{\infty}
$$

which leads to Eqn 9:

$$
M_{t}=M_{\infty}(1-\exp (-t / \tau))
$$

$\tau$ being a characteristic time for the process which is proportional to $l^{2} / D$. Eqn 9 shows some similarity to Eqn 6 and indeed by writing $\tau$ in the form of Eqn 10 :

$$
\tau=41^{2} / D \pi^{2}
$$

and using a correction of about $10 \%$ we could satisfactorily use Eqns 9 and 10 for evaluating the measurements and calculating a relevant value for $D$ (in fact this is the diffusivity $F($ s) defined by Eqn 4 ).

\section{Horizontal absorbency measurements}

Most measurements were made with an initial zero static pressure. Because the smallest measurable time interval was 0.1 or $0.4 \mathrm{~s}$, the short-term solution could not be used; so Eqns 9 and 10 were used for evaluation. Some typical results are reported below.

1. Comparison with the results reported by Miller [11] shows that an induction time $t_{\mathrm{i}}$ was not found; also hardly any part of the $M_{t}$ curve was linear and only once assumed a typical $S$ shape. These effects are probably due to the extensive slowing down of the whole process caused by starting with a large negative pressure gradient. Many effects indeed disappear when this pressure gradient approaches zero.

2. Using two different filter coefficients was found to have a major impact on absorption speed: for $C_{f}=2$ $\mathrm{mg} / \mathrm{s}, \mathrm{cm}^{2}, \mathrm{cmH}_{2} \mathrm{O} \tau$ was in the range $30-40 \mathrm{~s}$ for different cotton qualities; for $C_{\mathrm{f}}=16 \tau$ was $0.4-1 \mathrm{~s}$. Almost no effect on $M_{\infty}$ was found.
3. Lowering the static pressure head from zero to a negative value $\left(2-3 \mathrm{cmH}_{2} \mathrm{O}\right)$ had relatively little influence on $\tau$ but could significantly lower $M_{\infty}$ (comparable with the determination of pore size distribution by mercury intrusion [17]). A combination of effects 2 and 3 may occur in foam finishing. Also a foam may act as a porous plate during drainage, inducing an extra dynamic pressure as a resistance to liquid flow.

4. The addition of surfactant to water may have different effects. For an unbleached, non-desized fabric it may enable absorption to take place which would be impossible with water alone. For a polyester nonwoven it may significantly enhance absorption speed (from $\tau=60 \mathrm{~s}$ to $\tau=40 \mathrm{~s}$ for $\mathrm{C}_{\mathrm{f}}=2$ at zero static pressure). For bleached cotton there is not much difference. Assuming absorption speed to depend on $\sigma \cos \theta[16,18]$, the lowering of surface tension from around 72 to around $30 \mathrm{mN} / \mathrm{m}$ implies a decrease of contact angle $\theta$. If the contact angle for surfactant solution is assumed to be very low $\left(0-15^{\circ}\right)$, a contact angle for water against cotton of about $65^{\circ}$ can be calculated $[19,20]$.

Trying to derive an approximation for the absorbency during foam application from the horizontal absorbency there are two options. One is to try to estimate $(\mathrm{dM} / \mathrm{d} t)_{t=0}$ directly from the measurements (Table 2 ). We see that the high-resistance porous plate lowers absorbency values. The second option is to use the long-term results found from Eqns 9 and 10 and to substitute them in the short-

\begin{tabular}{|c|c|c|c|c|c|}
\hline \multirow{2}{*}{$\begin{array}{l}C_{1} \\
\left(\mathrm{mg} / \mathrm{s}, \mathrm{cm}^{2},\right. \\
\left.\mathrm{cmH}_{2} \mathrm{O}\right)\end{array}$} & \multirow{2}{*}{$\begin{array}{l}\text { Static } \\
\text { pressure } \\
\left(\mathrm{cmH}_{2} \mathrm{O}\right)\end{array}$} & \multirow{2}{*}{$\begin{array}{l}\text { Solution } \\
(\% / s)\end{array}$} & \multirow{2}{*}{$\mathrm{d}\left(M_{\mathrm{t}} / M_{\infty}\right) / \mathrm{d} t$} & \multicolumn{2}{|c|}{ Wet pick-up } \\
\hline & & & & in $2 \mathrm{~ms}$ & in $50 \mathrm{~ms}$ \\
\hline 2 & 0.0 & Water & 10 & 0.02 & 0.5 \\
\hline 2 & 0.0 & $\begin{array}{l}\text { Lauryl- } \\
\text { sulphate }\end{array}$ & 10 & 0.02 & 0.5 \\
\hline 16 & -0.2 & Water & 400 & 0.8 & 20 \\
\hline 16 & -1.0 & Water & 220 & 0.4 & 11 \\
\hline 16 & -2.0 & Water & 180 & 0.4 & 9 \\
\hline 16 & -3.0 & Water & 130 & 0.3 & 7 \\
\hline
\end{tabular}
term Eqn 5. This gives absorption values of the same order of magnitude $(1-8 \%)$. The advantage of this solution is that it accounts for a better time dependence $\left(-t_{c}{ }^{1 / 2}\right)$ than the linear approximation given in Table 2.

Table 2 Horizontal absorption and wet pick-ups

\section{Absorbency during foam application}

Neglecting the difference between absorption from the pure liquid phase and from a foam phase, one of the Eqns 5,6 or 9 can be taken as the typical absorption function of a substrate, $M_{t}$ in $\mathrm{kg} / \mathrm{m}^{2}$. This function can be transformed to a dynamic foam absorption equation (Eqn 11):

$$
\phi_{\mathrm{abs}}=\frac{M_{t} \lambda v}{\rho_{\mathrm{f}}}
$$


This absorption can be inserted into Eqn 2 by substituting $\phi_{\mathrm{v}}$ by $\phi_{\mathrm{v}}$ (effective) $=\phi_{\mathrm{v}}$ (input) $-\phi_{\mathrm{abs}}$. Although Eqn 11 contains a time dependent factor $\phi_{\mathrm{abs}}$, it was found experimentally that many applications could be adequately described by Eqn 12:

$$
\phi_{\mathrm{abs}}=K^{\prime} v
$$

The substitution of Eqn 12 into Eqn 2 has some important consequences:

1. At fabric speeds greater than 0 , the pressure drop will generally be lower than without absorption

2. At foam flows greater than 0 , it is in principle possible to obtain a zero pressure drop

3. The boundary condition separating the two parts of the model changes because $K$ must be replaced by $K+$ $K^{\prime}$. This means that at constant flow rate $\phi_{\mathrm{v}}$ the boundary speed will be lower (Figure 5).

Although $K$ and $K^{\prime}$ have the same dimension $\left(\mathrm{m}^{2}\right)$ and must be added to find the correct boundary condition, they are different in principle. $K$ is only a geometrical constant accounting for the degree of filling of the capillaries in the substrate. $K^{\prime}$ on the other hand accounts for the absorbency or disappearance of foam. Despite this difference, in effect they are supplementary. $K$ lowers foam pressure build-up by offering more substrate volume (foam flow porosity); $K$ 'lowers pressure build-up by lowering foam volume, in fact by taking up foam volume into the yarns (non-foam flow porosity).

Since our work is a continuation of the research done by Bryant [21], we can evaluate his results in terms of our extended model. The absorbencies defined by Eqns 11 and 12 have been called the dynamic sorption rate (DSR) by Bryant and he found this to be the reason for zero pressure drop during foam application. He evaluated DSR as a dynamic sorption capacity (DSC) at equilibrium contact time (ECT) and at two fabric velocities. ECT was defined as the situation where $\phi_{v}$ (input) $-\phi_{a b s}=0$. This evaluation, however, appears to be somewhat misleading since contact time $\left(t_{c}\right)$ and contact length $(b)$ are changed simultaneously. Therefore we present Bryant's original results together with our interpretation (Figure 6). From this it appears that at constant speed the DSR proportional to $b^{1 / 2}$ or $t_{c}^{1 / 2}$, which can be transformed to Eqn 13:

which is quite similar to a combination of Eqns 5 and 11. The effect of velocity variation at constant slit length shows that the short contact time leads to less absorption, and less than expected from Eqns 5 and 11. Thus higher fabric speed may induce enhanced absorption, as Bryant has already suggested.

\section{Pre-wetting}

An interesting combination of effects occurs with foam application on pre-wetted fabrics. Pre-wetting may be
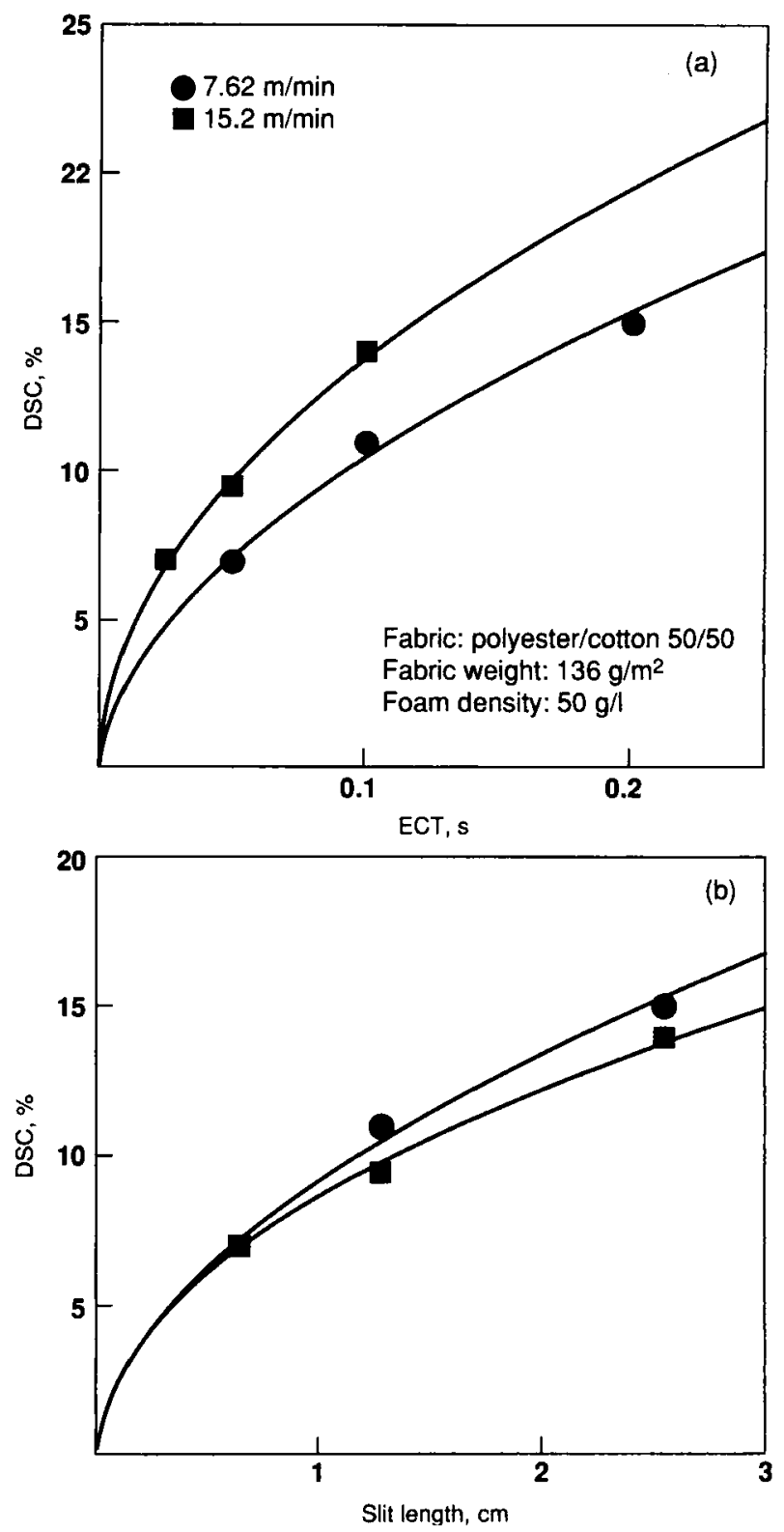

Figure 6 Dynamic sorption: (a) according to Bryant, (b) according to alternative representation

accomplished either by spattering water onto the running fabric (Figure 7) or by preliminary foam application (Figure 8). From pre-wetting with water, we have found that the main effect is to induce a pressure increase, probably caused by swelling, leading to a smaller mean hole diameter for foam flow. From pre-wetting with foam solution, a similar effect might be expected, in combination with other effects. Experiments have shown that surfactant addition to the pre-wetting liquid can dramatically lower foam application pressure. Because the effect occurs over a large pre-wet pick-up range (15$60 \%$ ) it cannot be adequately explained by a single cause. At lower pre-wet pick-up levels absorbency may be enhanced by lowering the contact angle between foam solution and fabric or by enlarging the spreading pressure $\pi_{\mathrm{sl}}$ if $\theta_{\mathrm{eq}}$ were already zero [14]. An absorbency promoting effect from pre-wetting agents was reported for wool by Trounson et al., which could increase to a factor of five in diffusivity [22]. 


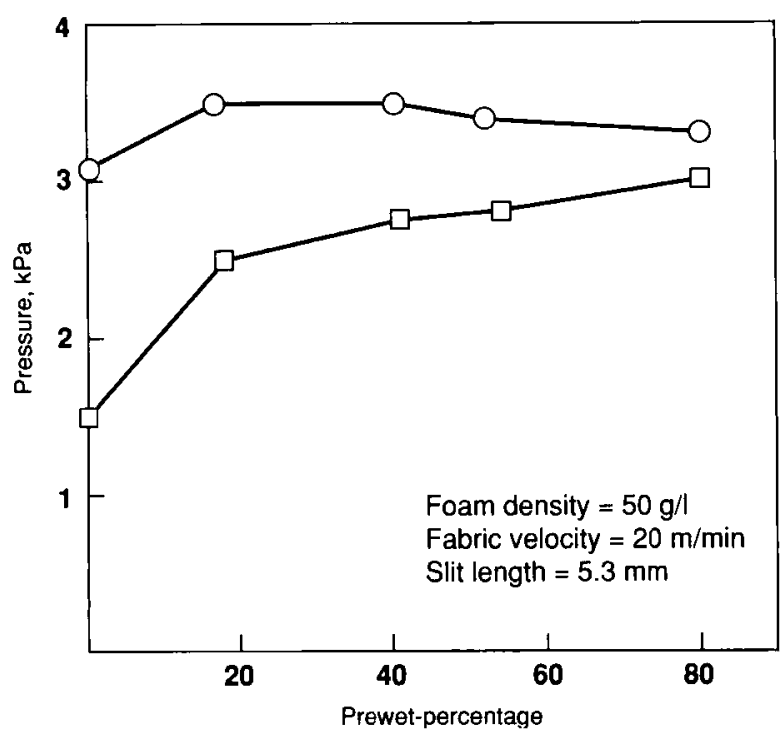

Figure 7 Foam application on water pre-wetted fabric

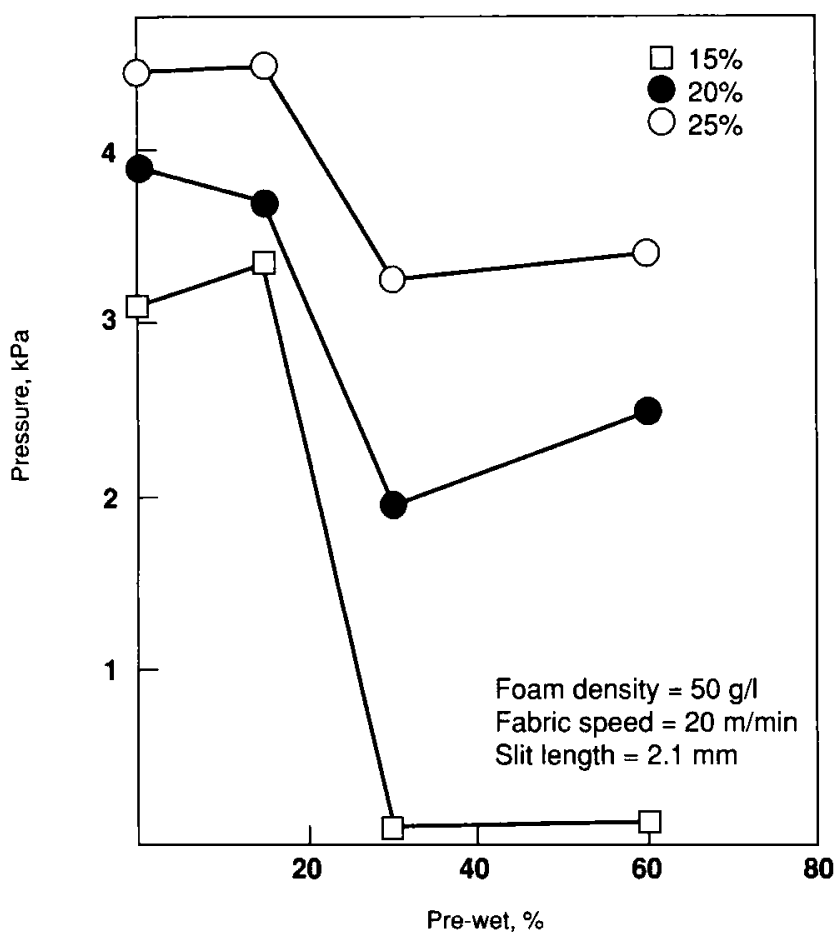

Figure 8 Foam application on foam pre-wetted fabric

At higher pre-wetting levels ( $>50 \%$ ) the total absorbing space is filled and the effect must be different from that of enhanced absorbency. Here liquid boundary flow may cause a pressure decrease to persist even at prewetting percentages of $30-60 \%$. The pressure drops found (also the ones reported by Isarin [3]) can be readily described by the $K^{\prime}$ parameter defined in Eqn 12, although the mechanism behind the pressure fall may change from absorbency to liquid boundary flow.

\section{CONCLUSION}

Starting with the relatively simple model of a $100 \%$ laminar foam flow through the capillaries of moving fabrics, several deviations from the model by foam application on different substrates can be demonstrated.

\section{Swelling and liquid retention}

Depending on their chemical nature and geometry, substrates may develop a higher resistance to foam flow caused by the changing geometry at high wet pick-up. Non-wovens can retain some water in regions of high capillarity and cotton-containing fabrics may show fibre swelling, causing the effective capillary diameter to become smaller.

\section{Liquid boundary flow}

An opposite effect of high wet pick-up may emerge with substrates with a relatively low contact area. A high water content can lead to viscous flow over a boundary layer of relatively low viscosity. When this layer is thick enough or of low enough viscosity this can lead to appreciable pressure fall, as has been found with most substrates at high wet pick-up.

\begin{abstract}
Absorbency
A typical characteristic of many textile assemblies is their capacity to absorb a certain amount of liquid in and between the fibres. When an appreciable absorptive capacity is coupled with a large absorption velocity this may be found to effect the pressure drop of foam forced into the assembly by foam degeneration caused by fast liquid absorption. This effect will be found for all applications within the absorptive capacity range, which for cotton is $0-50 \%$ wet pick-up.

From the results presented the relative importance of these phenomena is clear: swelling and liquid retention may cause deviations of up to $20 \%$. Change from $100 \%$ foam flow to partial boundary flow probably leads to deviations of up to $10 \%$ for cotton and $30 \%$ for smooth filaments. These deviations may be the reason why measurements on stationary substrates cannot be used without further adjustments for the evaluation of movement. It is clear that absorbency, whether of the untreated substrate or from a pre-wetted substrate, may give rise to the largest possible deviations. This effect has been described semi-quantitatively and will probably prove to be important in many foam finishing operations, as well as in other processes where liquid is added to a textile assembly.
\end{abstract}

\section{REFERENCES}

1. J T E Lemmen and J Groot Wassink, J.S.D.C., 106 (1990) 142.

2. J T E Lemmen, In preparation.

3. J C Isarin and J J de Boer, TNO Fibre Research Institute, internal report.

4. J T E Lemmen and J Groot Wassink, J.S.D.C.,106 (1990) July

5. A B J Kroezen and J Groot Wassink, J.S.D.C.,103 (1987) 386.

6. W E Morton and J W S Hearle, Physical properties of textile fibres (Manchester: Textile Institute, 1975).

7. J E Ford, Fibre data summaries (Manchester: Shirley Institute, 1968).

8. J H Perry, Chemical engineers' handbook (New York: McGraw-Hill, 1963).

9. KRietema, Fysische transport en overdrachtsverschijnselen, Het Spectrum (1976).

10. A B J Kroezen, J Groot Wassink and C A C Schipper, J.S.D.C., 104 (1988) 393.

11. B Miller and I Tyomkin, Text. Research J., 54 (1984) 706. 
12. J Szekely and A W Neumann, J. Coll. Interface Sci, 35 (2) (1971) 273.

13. S Chwastiak, I. Coll. Interface Sci., 42 (2) (1973) 298

14. P K Chaterjee, Absorbency (Elsevier, 1985).

15. J Crank, The mathematics of diffusion (Oxford: OUP, 1970).

16. E W Washburn, Phys. Rev., 17 (1921) 273.

17. M Maejima, Text. Research J., 53 (1983) 427.

18. E Schollmeyer, Melliand Textilber., 63 (1982) 721.

19. Vlisco BV Helmond (The Netherlands), internal research report (Mar 1988).

20. W Volz, PhD thesis, Deutsche Institute für Textil und Faserforschung, Stuttgart (1985).

21. G M Bryant, Text. Research J., 54 (1984) 217.

22. M E Trounson and J R McLaughlin, Text. Research J., 58 (1988) 455.

\section{SYMBOLS}

C coefficient of resistance

$C_{\mathrm{f}}$ filter coefficient

$D$ diffusion coefficient

$F(\mathrm{~s})$ diffusivity

$k$ consistency

$K$ porosity constant

$K^{\prime}$ absorption constant

$L, l$ fabric thickness or partial

penetration of fabric thickness
$\operatorname{Pa~s}^{n} \mathrm{~m}^{-3 n}$

$\mathrm{kg} \mathrm{s}^{-1} \mathrm{~Pa}^{-1} \mathrm{~m}^{-2}$

$\mathrm{m}^{2} \mathrm{~s}^{-1}$

$\mathrm{m}^{2} \mathrm{~s}^{-1}$

$\mathrm{Pa} \mathrm{s}^{n}$

$\mathrm{m}^{2}$

$\mathrm{m}^{2}$

$\mathrm{m}$
$M_{t}$ mass absorbed at time $\mathrm{t}$

$M_{\infty}$ mass absorbed at infinite time pseudoplastic index

pressure drop

capillary radius

fabric area

saturation

time

fabric velocity

distance

shear rate

fabric porosity for foam

viscosity

contact angle

slit length

fabric density

foam density

surface tension

mass flow

volume flow

shear stress

characteristic time $\mathrm{kg}$

$\mathrm{kg}$

$\mathrm{Pa}$

$\mathrm{m}$

$\mathrm{m}^{2}$

$s$

$\mathrm{m} \mathrm{s}^{-1}$

$\mathrm{m}$

$\mathrm{s}^{-1}$

Pas

rad

$\mathrm{m}$

$\mathrm{kg} \mathrm{m}^{-2}$

$\mathrm{kg} \mathrm{m}^{-3}$

$\mathrm{N} \mathrm{m}^{-1}$

$\mathrm{kg} \mathrm{s}^{-1}$

$\mathrm{m}^{3} \mathrm{~s}^{-1}$

$\mathrm{Pa}$

\section{LETTERS}

\section{Younger members}

\section{From David Blackburn}

It is probably significant that I am now taking longer to read the Journal, in that there are more articles of genuine interest to me. Whilst this fact may be a plaudit to the Journal Committee, it is also my excuse for responding somewhat tardily to views expressed in the Profile of Jim Park published in the September issue [1].

Jim 'believes that there should not only be more younger members introduced into the system but that they should be given increased powers in the decision making process'. I suspect that many others in the Society agree with him - I certainly do. Ever since I took up my first committee chairmanship (and that's further back than I care to remember) I have sought to recruit younger committee members. In common with other like-minded chairmen, I have not been very successful.

How can we improve the situation? Jim wonders if having committee meetings out of hours might help. I have mixed feelings about this. Certainly, we would know we had dedicated members if it were successful, but, if attendances at regional evening meetings are any guide, it's rather a long shot. Rationalising the committee structure is another of Jim's suggestions and I interpret this as saying 'fewer committees are necessary'. When I see how often the same subject is debated by different committees I'm inclined to agree but the system does allow a lot of voices to be heard and militates against power being concentrated in too few hands.

To try to be more positive, I would like to float the idea of 'observer status' which I have encountered in other bodies. Thus someone who may be interested joining a particular committee attends a couple of meetings as an observer. This does not mean that the observer's only function is to sit with ears and eyes open and mouth shut. An interested observer would be able to query aspects of the discussions without feeling too much responsibility. They may also feel more able to accept an invitation to attend a committee without commitment and the experience may allow them to overcome their doubts.

Any takers?

DAVID BLACKBURN Leeds, UK

\section{REFERENCE}

1. J.S.D.C., 107 (1991) 308.

\section{Light fastness testing}

\section{From Dr C T Page}

May I suggest a little caution before some of the changes advocated by MrStead in his letter in the November 1991 issue are taken any further [1].

Presumably Mr Stead is speaking principally about textile dyes when he comments that the light fastness levels 1,2 and 3 are of little practical significance. In the case of leather and paper dyes these levels are very important, and should be retained. For example, for a dye to reach a light fastness of 3 for leather is considered relatively good.

So please don't forget dyes are used on substrates other than textiles when suggesting changes.

CAMPBELL PAGE

REFERENCE

Basel, Switzerland

1. E Stead, J.S.D.C., 107 (1991) 414. 